\title{
Correlação Clínico-Radiográfica \\ Caso 5/2004 - Adolescente de 16 anos com anomalia de Ebstein Instituto do Coração do Hospital das Clínicas da FMUSP
}

\author{
Edmar Atik \\ São Paulo, SP
}

Dados clínicos - Adolescente de 16 anos de idade do sexo feminino e de cor branca, sabe ser portadora de cardiopatia congênita (anomalia de Ebstein). 0 quadro sintomático iniciou-se nas primeiras horas de vida quando desenvolveu hipóxia e insuficiência cardíaca acentuadas mas rapidamente reversíveis nos dias subseqüentes após tratamento com prostaglandina E1, digital e diuréticos. Desde então, manteve-se assintomática em plena atividade física e apresentando bom desenvolvimento pôndero-estatural. Realizou recentemente ergoespirometria cujo consumo máximo de oxigênio foi de $29 \mathrm{ml} / \mathrm{kg} / \mathrm{min}, 20 \%$ abaixo dos níveis esperados para a idade. Ao exame físico estava em bom estado geral, acianótica, eupnéica, corada e com pulsos normais. A pressão arterial era de 100/70 mmHg, a freqüência cardíaca de 80 bpm, 0 peso de $70 \mathrm{~kg}$ e a altura de $168 \mathrm{~cm}$.

Não havia turgência jugular e a aorta não foi palpada na fúrcula. No precórdio havia discretas impulsões na borda esternal esquerda. 0 ictus cordis era difusamente palpado no $4^{\circ}$ e $5^{\circ}$ espaços intercostais esquerdos. 0 ritmo cardíaco estava a 4 tempos. Auscultava-se sopro sistólico $+/++$ e sopro diastólico + no $3^{\circ}$ e $4^{\circ}$ espaços intercostais esquerdos e na área mitral. 0 fígado não foi palpado.

O eletrocardiograma mostrou ritmo sinusal e sinais de bloqueio completo do ramo direito, com QRS alargado $(0,13$ ") e espessado, com nítido retardo final. Complexo qR em V1 e em V2, polifásico de $\mathrm{V} 3$ a V5, com onda r pequena. A onda T se mostrou negativa de V1 a V4. SÂP: + 70 ${ }^{\circ}$ SÂQRS: $+140^{\circ}$, SÂT: $-20^{\circ}$.

Imagem radiográfica - Mostra área cardíaca aumentada (ICT: 0,63 ) às custas do átrio direito e do ventrículo direito. Os arcos inferiores são arredondados e alongados sendo o arco médio ligeiramente abaulado. A trama vascular pulmonar é nitidamente diminuída, principalmente na periferia (fig.1).

Impressão diagnóstica - Esta imagem sugere o diagnóstico de cardiopatia congênita com hipofluxo pulmonar em decorrência de insuficiência tricúspide, em grau acentuado, como ocorre usualmente na anomalia de Ebstein.

Diagnóstico diferencial - Outras causas de insuficiência tricúspide com hipofluxo pulmonar devem ser lembradas como em cardiopatias cianogênicas com associação de defeitos como no ventrículo único e estenose pulmonar com insuficiência da valva $\mathrm{AV}$ à direita. Ademais, também na estenose pulmonar valvar acentuada com insuficiência tricúspide, na atresia pulmonar com sep-

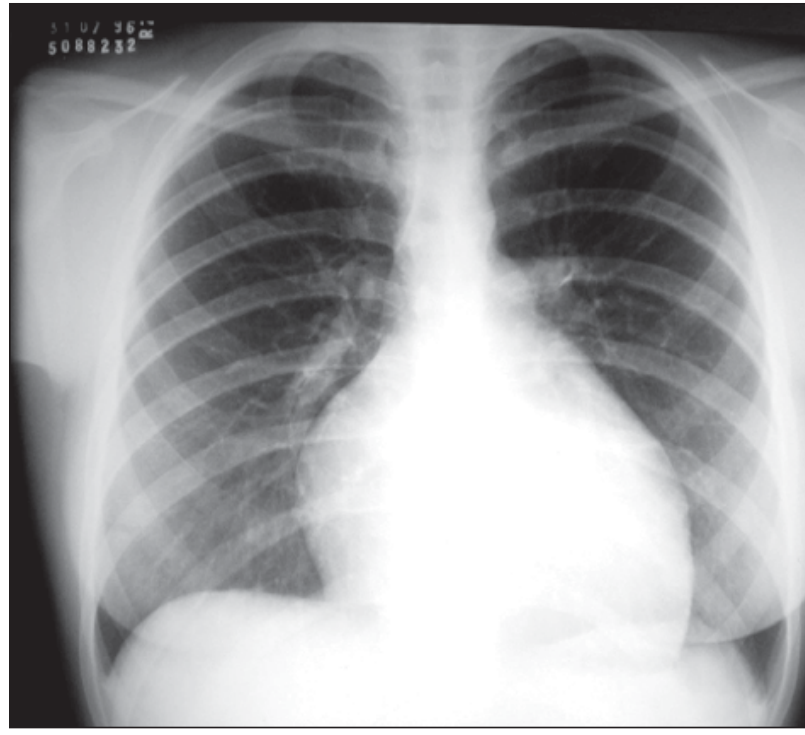

Fig. 1 - Radiografia de tórax salienta acentuado aumento da área cardíaca às custas das cavidades direitas com trama vascular pulmonar diminuída.

to ventricular íntegro e ainda na insuficiência tricúspide por agenesia valvar, total ou parcial, e ainda no aneurisma isolado do átrio direito.

Confirmação diagnóstica - A evolução natural clínica na anomalia de Ebstein é em geral mais prolongada que nas demais anomalias consideradas acima. Este elemento, ao lado do bloqueio completo do ramo direito encontrado no ECG e que raramente ocorre nas outras anomalias, sugerem o diagnóstico da anomalia de Ebstein. 0 ecocardiograma observou as alterações características desta anomalia com redundância valvar e implantação baixa no septo ventricular, falha de coaptação valvar e dilatação do anel tricúspide. A insuficiência tricúspide era acentuada com aumento pronunciado das cavidades direitas. A pressão sistólica calculada da artéria pulmonar era de $25 \mathrm{mmHg}$ e o ventrículo direito media $63 \mathrm{~mm}$ no maior diâmetro.

Conduta - À operação, a plástica valvar não foi possível dada a malformação acentuada das cúspides da valva tricúspide. A falta de coaptação das cúspides obrigou à troca valvar por valva biológica com resultado benéfico dado que houve redução do tamanho do ventrículo direito para $25 \mathrm{~mm}$, cerca de um ano após a intervenção. 